\title{
A LA MEMORIA DE MARÍA CRISTINA ÁLVAREZ LOMELÍ
}

Fue para nosotros de profunda tristeza enteramos, el viemes 6 de abril de 1990, de la imprevista desaparición física de la maestra María Cristina Alvarez Lomelf, destacada lingüista y excolaboradora nuestra en el Centro de Estudios Mayas.

La sefiora Cristina, como era conocida entre nosotros, nacio en Altotonga, Veracruz, el 28 de marzo de 1925 y curso sus estudios superiores en la ciudad de México para más adelante trasladarse a Jalapa, en donde ingreso a la Escuela Normal Veracruzana y acredito la carrera de Maestra Normalista con la especialidad de educadora. Posteriormente regres 6 a la capital del país para estudiar Antropología, en la Escuela Nacional de Antropología e Historia del la que obtuvo el tutulo de lingüista, con su disertación titulada Descripción estructural del maya del Chilam Balam de Chumayel, en junio de 1967.

Participo como investigadora en el Seminario de Estudios de la Escritura Maya de la Universidad Nacional Autónoma de México y en el Departamento de Lingüística del Instituto Nacional de Antropología e Historia. Después laboró en el Centro de Estudios Mayas y en el Instituto de Investigaciones Antropologicas, de nuestra máxima casa de estudios.

Mostro interés por los sistemas de parentesco de los mayas y, bajo la dirección de Isabel Kelly, llevó a cabo investigaciones etnográficas en el Tajín. Además, dentro de su ejercicio profesional, hizo incursiones en el campo de la epigrafía.

Como investigadora del Seminario de Estudios para la Escritura Maya trabajó con el maya yucateco clásico, en especial el de los libros de Chilam Balam y de los diccionarios coloniales. 
Realizo una traducción y una descripción estructural del maya yucateco del Chilam Balam de Chumayel (1969). Cabe recordar que en 1970 apareció su Diccionario de los elementos del maya yucateco colonial. De particular relevancia es su colaboración en el volumen X de Estudios de Cultura Maya titulada "Estudio fonológico de los radicales del maya yucateco colonial." En 1981 y 1984 se publican dos volúmenes de su Diccionario etnolingǘstico del idioma maya yucateco colonial: Mundo físico y Aprovechamiento de los recursos naturales, respectivamente. Estos dos trabajos los elaboró a partir de los materiales que habra estudiado y de los diccionarios de Pío Pérez y Motul.

Hacia la segunda mitad de la década de los setentas aparecen sus trabajos "Estructura del idioma en que se escribieron los codices mayas" (1976) y dos años después "Idioma y cultura en el descifre de la escritura maya". Ambos fueron publicados por el Centro de Estudios Mayas y, en ellos, se refleja su deseo por dilucidar las mentalidad del pueblo creador de tales manifestaciones culturales.

A su tiempo, experimento los nuevos avances para descifrar los textos mayas, con la utilización de máquinas electrónicas. En 1980 impartió un curso acerca de las posibles lecturas en maya yucateco del Códice Dresde, a estudiantes de doctorado en la Universidad Estatal de Nueva York en Albany.

Los abundantes títulos y variados temas de las disertaciones sustentadas por ella, la distinguieron como notable ponente y conferencista. Se pueden mencionar brevemente: "Una nueva técnica para el descifre de la escritura maya", ponencia presentada en la XIII Mesa Redonda de la Sociedad Mexicana de Antropologfa (1973), en Jalapa, Veracruz y "Bases lingüísticas para los estudios de la literatura maya", conferencia dictada en el Primer Congreso sobre el Popol Vuh, celebrado en Santa Cruz del Quiché, Guatemala, en 1977.

Por otra parte, cabe destacar la gran vocación de la Mtra. Alvarez Lomelí por la enseñanza, prueba de ello es la gran cantidad de cursos que impartio, tanto en México, como en el extranjero. 
Su bibliografía incluye diversos libros, cuadernos y artículos especializados en la lengua maya, al estudio de la cual dedicaría más de veinte affos de su vida. La última de sus investigaciones, Código semiologico de la escritura maya, se encontraba en preparación.

Estara por siempre grabado en nuestra memoria el grato recuerdo de su presencia y amistad.

Comisión Editorial del Centro de Estudios Mayas 


\section{BIBLIOGRAFIA}

Descripción estructural del maya del Chilam Balam de Chumayel, UNAM, Seminario de Estudios para la Escritura Maya, México, 1969 (Cuadernos, 1).

"Investigación de los radicales del maya yucateco colonial", Anales de Antropologia, Instituto Nacional de Antropología e Historia, México, 1969.

Diccionario de elementos del maya yucateco colonial, en colaboración con M. Śwadesh y J. R. Bastarrachea, UNAM, Seminario de Estudios para la Escritura Maya, México, 1970 (Cuadernos, 3).

Textos coloniales del Libro de Chilam Balam de Chumayel y textos gllficos del Códice de Dresde, UNAM, Centro de Estudios Mayas, México, 1974 (Cuadernos, 10).

"Estructura del idioma en que se escribieron los códices mayas", Estudios de cultura maya, vol. X, UNAM, Centro de Estudios Mayas, México, 1976-1977.

"Estudio fonologico de los radicales del maya yucateco colonial", Estudios de cultura maya, vol. X, UNAM, Centro de Estudios Mayas, México, 1976-1977.

"Idioma y cultura en el descifre de la escritura maya", Estudios de cultura maya, vol. XI, UNAM, Instituto de Investigaciones Filologicas, Centro de Estudios Mayas, México, 1978.

Diccionario etnolingülstico del idioma maya yucateco colonial, vol. I. Mundo físico, UNAM, Instituto de Investigaciones Filologicas, Centro de Estudios Mayas, México, 1981.

Diccionario etnolingǘstico del idioma maya yucateco colonial, vol. II Aprovechamiento de los recursos naturales, UNAM, Instituto de Investigaciones Filológicas, Centro de Estudios Mayas, México, 1984. 